\title{
Caracterização química, física e mineralógica do produto granulado de manganês proveniente da Mina do Azul
}

\author{
FARIA, G. L ${ }^{\mathrm{I}}$, REIS, E. LII, JANOTTI JR., N. ${ }^{\text {III }}$, ARAÚJO F. G. S. ${ }^{\text {IV }}$

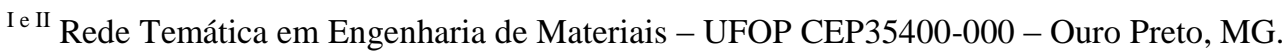 \\ e-mail: geraldolfaria@yahoo.com.br ; ericasier@bol.com.br \\ III VALE Manganês - Águas Claras, Nova Lima, MG. \\ e-mail: nelson.jannotti@vale.com \\ ${ }^{\text {IV }}$ Dep. Física, REDEMAT/UFOP CEP35400-000 - Ouro Preto, MG. \\ e-mail: fgabrielaraujo@uol.com.br
}

\section{RESUMO}

Os minérios de manganês provenientes da mina do Azul são importante matéria-prima na produção de ferro-ligas de manganês. Visando melhorias no beneficiamento e no processo de fabricação destas ligas, foi realizada a caracterização do produto Granulado da unidade do Azul-VALE/Manganês. Foi obtida uma amostra representativa desta mina e realizada análise granulométrica, onde se verificou a ocorrência de $80 \%$ das partículas abaixo de $22,6 \mathrm{~mm}$ e $50 \%$ abaixo de $12,5 \mathrm{~mm}$. Considerou-se como granulado a fração menor que $37,5 \mathrm{~mm}$ e maior que $6,3 \mathrm{~mm}$, que é a mais abundante neste minério e comumente destinada às usinas de ferro-ligas. A fração entre $37,5 \mathrm{~mm}$ e $6,3 \mathrm{~mm}$ foi amostrada e foram realizadas análises termogravimétrica, química dos elementos majoritários e identificadas as fases minerais presentes. A análise térmica (TG-DTA) identificou perda de massa em torno de $300^{\circ} \mathrm{C}, 500^{\circ} \mathrm{C}, 700^{\circ} \mathrm{C}, 900^{\circ} \mathrm{C}$ e $1000^{\circ} \mathrm{C}$ associadas à decomposição térmica de algumas fases minerais presentes. Os teores de $\mathrm{Mn}, \mathrm{Fe}$ e $\mathrm{SiO}_{2}$ foram respectivamente, 47,68; 3,59; e 3,16\%. O produto Granulado da unidade do Azul é composto majoritariamente pelos minerais de manganês criptomelana $\left[\mathrm{KMn}_{8} \mathrm{O}_{16}\right]$ e pirolusita $\left[\mathrm{MnO}_{2}\right]$. Os constituintes minoritários são todorokita $\left[(\mathrm{Na}, \mathrm{Ca}, \mathrm{K})_{2} \mathrm{Mn}_{6} \mathrm{O}_{12} \cdot 3-4.5\left(\mathrm{H}_{2} \mathrm{O}\right)\right]$, magnetita[ $\left.\mathrm{Fe}_{3} \mathrm{O}_{4}\right]$ e gibbsita $\left[\mathrm{Al}(\mathrm{OH})_{3}\right]$ (A pirolusita, a magnetita e a gibbsita foram identificadas por microscopia óptica).

Palavras-chave: Minério de manganês, produto granulado, caracterização, Mina do Azul.

\section{Chemical, physical and mineralogical characterization of Azul Mine manganese lump product}

\section{ABSTRACT}

The manganese ores from Azul mine are important raw materials for ferro alloys production. For improvements in the manganese ferro alloys production, Azul's lump ore product was characterized. A representative sample from the mine has been obtained and their particle sizes were classified. The size distribution showed that $80 \%$ of particles were below $22.6 \mathrm{~mm}$ and $50 \%$ were below $12.5 \mathrm{~mm}$. The particles with sizes between $37.5 \mathrm{~mm}$ and $6.3 \mathrm{~mm}$ were named lump ore product. The fraction between $37.5 \mathrm{~mm}$ and $6.3 \mathrm{~mm}$ was submitted to chemical and mineralogical characterization. The TGA tests showed weight losses in $300^{\circ} \mathrm{C}, 500^{\circ} \mathrm{C}, 700^{\circ} \mathrm{C}, 900^{\circ} \mathrm{C}$ and $1000^{\circ} \mathrm{C}$ due, mainly, the high manganese oxides decompositions. The Mn, $\mathrm{Fe}$ and $\mathrm{SiO}_{2}$ contents were, respectively, 47.68\%; 3.59\% and 3.16\%. Azul's lump product has cryptomelane $\left[\mathrm{KMn}_{8} \mathrm{O}_{16}\right]$ and pyrolusite $\left[\mathrm{MnO}_{2}\right]$ as main mineralogical constituents. todorokite $\left[(\mathrm{Na}, \mathrm{Ca}, \mathrm{K})_{2} \mathrm{Mn}_{6} \mathrm{O}_{12} \bullet 3-4.5\left(\mathrm{H}_{2} \mathrm{O}\right)\right]$, magnetite $\left[\mathrm{Fe}_{3} \mathrm{O}_{4}\right]$ and gibbsite $\left[\mathrm{Al}(\mathrm{OH})_{3}\right]$ appear as minor constituents (Pyrolusite, magnetite e gibbsite were identified by optical microscopy).

Keywords: Manganese ore, lump product, characterization, Azul Mine. 


\section{INTRODUÇÃO}

O Mn é um dos grandes destaques da indústria de ferro ligas mundial. Aproximadamente $90 \%$ de todo manganês produzido no mundo está na forma de ferro ligas de manganês, das quais pelo menos $98 \%$ são consumidas pela indústria do aço [1]. O manganês, adicionado na forma de ferro liga, é um importante elemento de liga do aço, auxiliando no refino da estrutura de grãos, aumentando a resistência mecânica e melhorando a temperabilidade e a ductilidade do aço. Em teores mais altos, o manganês, associado a teores mais elevados de enxofre, facilita a usinagem, melhorando o acabamento superficial dos aços [2] e [3]

Os minérios Granulados de manganês ainda são amplamente utilizados como matéria-prima para produção das ferro ligas de manganês. As misturas destes minérios, provenientes de diversas minas ou mesmo de diferentes frentes de lavra de uma mesma mina, são, nas usinas de ferro ligas, usualmente definidas de acordo unicamente com as suas características químicas e granulométricas [4].

Um problema frequentemente encontrado na rotina de operação dos fornos metalúrgicos de produção das ligas de manganês é o desconhecimento das características físicas e mineralógicas dos Granulados de minérios. Neste contexto, este trabalho teve como objetivo caracterizar, química, física e mineralogicamente o produto Granulado de manganês da mina do Azul-VALE/Manganês [4].

Neste contexto, alguns autores veem apresentando importantes contribuições científicas com relação ao desenvolvimento de metodologias de caracterização que possibilitem correlacionar as propriedades metalúrgicas dos minérios de manganês às suas características físicas, químicas e mineralógicas. REIS et al. (2010), SONRENSEN et al. (2010) e FARIA et al. (2012) propuseram pioneiramente, metodologias baseadas na definição tipológica dos minérios e nas transformações das fases minerais dos minérios durante aquecimento em atmosfera oxidante [5], [6] e [7].

REIS et al. (2010) propuseram uma metodologia de caracterização de minérios hidratados de manganês e a aplicaram em uma tipologia da mina do Azul denominada Maciço. O minério estudado por eles se caracteriza por ser uma frente de lavra específica com elevado teor de manganês (53\%), mas que por questões estratégicas, não é comercializado diretamente e sim misturado a outras tipologias dando origem ao Produto Granulado que é colocado à disposição no mercado. Segundo REIS et al. (2010), os minerais constituintes majoritários desta tipologia são a criptomelana e a pirolusita, entretanto este trabalho não faz uso da conjugação das técnicas de DRX, MEV e MO para observar e semiquantificar as fases [5].

SONRENSEN et al. (2010) caracterizaram mineralogicamente e estudaram a decomposição térmica de diferentes tipos de minério, entre eles de um proveniente da Mina do Azul. Segundo os autores, este minério é constituído majoritariamente por óxidos e hidróxidos, sendo a fase majoritária a nsutita (hidróxido de manganês). SONRENSEN et al. (2010) afirmaram que durante aquecimento ao ar, as óxidos de maior estado de oxidação e os hidróxidos se decompõem em fases mais estáveis como $\mathrm{Mn}_{3} \mathrm{O}_{4}$ e $\mathrm{Mn}_{2} \mathrm{O}_{3}$ e que estas decomposições, por serem exotérmicas, são de extrema importância para o perfil térmico do reator metalúrgico [6].

FARIA et al. (2012) estudaram o fenômeno de crepitação em três importantes minérios de manganês do Brasil. Segundo os autores, o comportamento de crepitação é uma função direta da composição mineral, sendo a eliminação de umidade e as decomposições térmicas das fases hidratadas e dos óxidos de maior estado de oxidação os fatores que mais contribuem para o fenômeno. Neste trabalho, os autores também caracterizaram um tipo de minério proveniente da mina do Azul. Segundo eles, este minério apresentou considerável índice de crepitação devido à eliminação de vapor de água proveniente da decomposição térmica das fases hidratadas (todorokita majoritariamente), entretanto, como a estrutura do minério é muito porosa, este efeito foi amortizado em relação aos minérios menos hidratados em virtude do alívio da pressão de vapor de água pelos poros abertos [7].

A mina de manganês do Azul é a maior produtora de minério de manganês da América Latina com produção anual de 2,5 Mtpa. O minério produzido visa principalmente a produção de ferro ligas e, em menor proporção, a indústria química e de baterias [8]. A Mina do Azul está localizada na porção centro-oeste da Província Mineral de Carajás, no interior da Floresta Nacional de Carajás, Município de Parauapebas, no sudeste do estado do Pará. O empreendimento situa-se a aproximadamente $37 \mathrm{~km}$ do Núcleo Urbano de Carajás e a $62 \mathrm{~km}$ do Município de Parauapebas. Com $5 \mathrm{~km}$ de extensão por $1 \mathrm{~km}$ de largura máxima, a cava final apresenta 280 ha de área impactada [8].

\section{MATERIAIS E MÉTODOS}

Obteve-se, na mina, uma tonelada de seu principal produto granulado. Esta amostra representativa foi recebida no Laboratório de Tratamento de Minérios da Fundação Gorceix/CT3 onde foi preparada para a caracterização química, física e mineralógica.

A amostra tal qual foi inicialmente homogeneizada e quarteada em pilha cônica, de forma a gerar amostras representativas para sua caracterização. A partir do montante recebido $(1.000 \mathrm{~kg})$, foram retirados 
$100 \mathrm{~kg}$ de amostra representativa, sendo $50 \mathrm{~kg}$ destinados aos procedimentos de preparação para caracterização e os $50 \mathrm{~kg}$ restantes a um arquivo interno. Esta alíquota foi britada em britadores de mandíbula até que todo o conteúdo estivesse abaixo de $6,3 \mathrm{~mm}$. Este material foi novamente quarteado e $1 \mathrm{~kg}$ destinado a uma nova britagem em britadores de mandíbulas. O produto da cominuição foi quarteado de forma que 500g foram amostrados e destinados ao moinho de disco fechado para pulverização.

O material já pulverizado foi quarteado e dividido em alíquotas representativas destinadas a análises químicas, físicas e mineralógicas.

As análises químicas quantitativas foram realizadas no Laboratório de Geoquímica/DEGEO/UFOP. A abertura das amostras foi feita em solução aquosa de ácido clorídrico 1:1 para determinação dos teores de $\mathrm{Mn}, \mathrm{Fe}, \mathrm{CaO}, \mathrm{MgO}, \mathrm{SiO}_{2}, \mathrm{Al}_{2} \mathrm{O}_{3}, \mathrm{TiO}_{2}$ e $\mathrm{P}$. Os teores de $\mathrm{Mn}$ e $\mathrm{SiO}_{2}$ foram determinados por titulometria e os demais componentes por ICP - OES em Espectrômetro de Emissão por Plasma Indutivamente Acoplado da marca SPECTRO/modelo Ciros CCD.

Os constituintes minerais da amostra foram identificados por meio de análise microscópica e difratometria de raios-x pelo método do pó total. Os equipamentos de difração de raios-x utilizados foram um difratrômetro modelo Rigaku, série D/Max-B, equipado com tubo de cobre e passo de varredura de $0,02^{\circ}$ do Laboratório de Difração de Raios-x do Departamento de Geologia da Universidade Federal de Ouro Preto, e outro marca Rigaku, modelo Geigerflex com tubo de cobre do Centro de Desenvolvimento da Tecnologia Nuclear (CDTN). A interpretação dos difratogramas foi feita através do software JADE 3.1 do fabricante MDI.

Para análises termogravimétricas, o equipamento utilizado foi uma termobalança Shimadzu, com controle e aquisição de dados por computador. As análises foram realizadas ao ar sintético, com elevação da temperatura desde ambiente até $1300^{\circ} \mathrm{C}$ a uma taxa constante de $5^{\circ} \mathrm{C} / \mathrm{min}$.

A amostra de minério foi seca a vácuo na temperatura de $250^{\circ} \mathrm{C}$ durante quatro horas. A densidade aparente foi determina por meio de duas técnicas distintas, que foram picnometria a álcool (vidraria específica) e micropicnometria a hélio (equipamento da marca Quantachrome). Análises de área superficial específica e de porosidade foram realizadas pelo método de adsorção de nitrogênio pelo equipamento NOVA 1000 Quantachrome.

\section{RESULTADOS}

A classificação granulométrica da amostra global nas malhas de 50,0; 37,5;6,3 e 1,18mm, da série Tyler está apresentada na Figura 1. Na distribuição granulométrica observa-se graficamente que $\mathrm{P}_{50}=12,5 \mathrm{~mm}$ e $\mathrm{P}_{80}=22,6 \mathrm{~mm}$, o que significa que $50 \%$ das partículas são passantes em $12,5 \mathrm{~mm}$, assim como $80 \%$ em $22,6 \mathrm{~mm}$. Observa-se ainda que este minério possui $100 \%$ de partículas passante em $37,5 \mathrm{~mm}$ e $9,8 \%$ passante em $1,18 \mathrm{~mm}$.

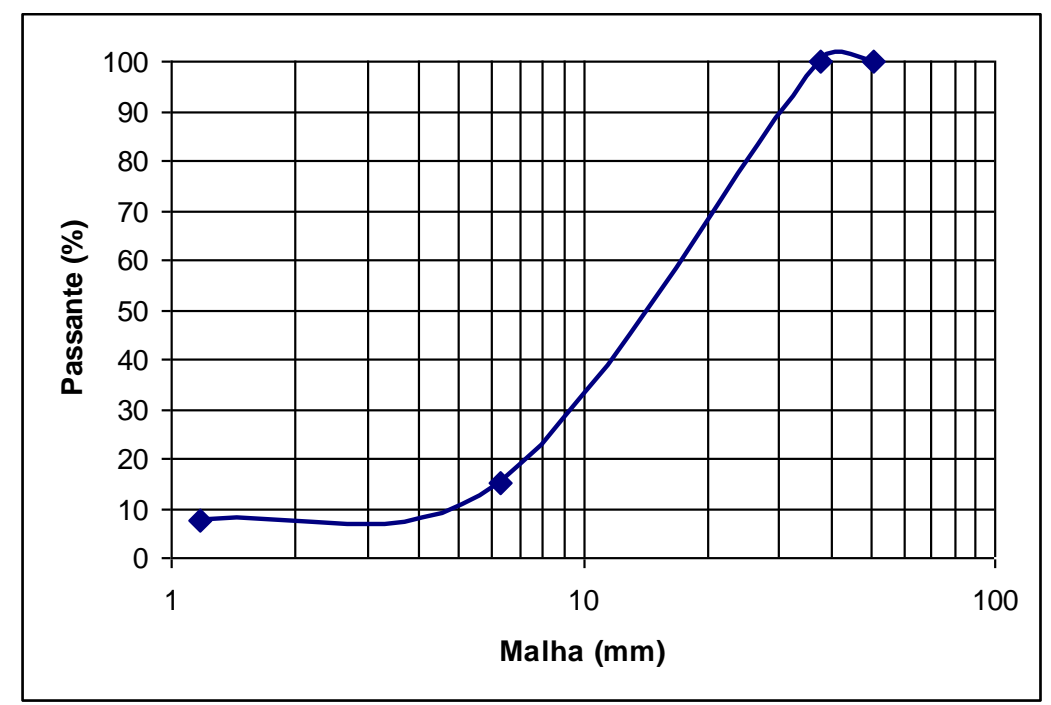

Figura 1: Distribuição granulométrica da amostra global do Produto Granulado de manganês proveniente da Mina do Azul. 
Os teores de $\mathrm{Mn}, \mathrm{Fe}$ total, $\mathrm{CaO}, \mathrm{MgO}, \mathrm{SiO}_{2}, \mathrm{Al}_{2} \mathrm{O}_{3}, \mathrm{TiO}_{2}$ e P estão apresentados na Tabela 1. Podese observar que o produto Granulado contém $47,68 \%$ de $\mathrm{Mn}$, que é superior a $35 \%$ (valor de referência no mercado de minérios de manganês), sendo, portanto, um minério de alto teor. A relação $\mathrm{Mn} / \mathrm{Fe}$ é da ordem de 13. Este valor é considerado elevado, e por isto permite maior liberdade na adição de cargas corretivas do teor de Fe no forno elétrico de redução, permitindo a utilização de materiais com menor custo no mercado.

A basicidade binária, calculada por meio da razão $\mathrm{CaO} / \mathrm{SiO}_{2}$, é da ordem de 0,04 . Este valor pode conferir características ligeiramente ácidas e de fluidez limitada à escória gerada no processo de fabricação das ligas. O teor de fósforo é um parâmetro de extrema importância, pois de forma geral, praticamente todo o teor deste elemento é transferido para as ligas e consequentemente para os aços, fragilizando-o. No minério estudado, o teor de fósforo é considerado baixo, da ordem de $0,1 \%$.

Tabela 1: Análise química do produto Granulado de manganês proveniente da Mina do Azul.

\begin{tabular}{c|c|c|c|c|c|c|c|c}
\hline Amostra & $\mathbf{A l}_{2} \mathbf{O}_{\mathbf{3}}(\%)$ & $\mathbf{C a O}(\%)$ & $\mathbf{F e}(\%)$ & $\mathbf{M g O}(\%)$ & $\mathbf{M n}(\%)$ & $\mathbf{P}(\%)$ & $\mathbf{T i O}_{\mathbf{2}}(\%)$ & $\mathbf{S i O}_{\mathbf{2}}(\%)$ \\
\hline $\begin{array}{c}\text { Granulado } \\
\text { do Azul }\end{array}$ & 5,22 & 0,12 & 3,59 & 0,18 & 47,68 & 0,097 & 0,24 & 3,16 \\
\hline
\end{tabular}

Os minerais identificados por difratometria de raios-x e semiquantificados por microscopia óptica de luz refletida, estão apresentados na Tabela 2. O produto Granulado da mina do Azul é composto majoritariamente por óxidos de $\mathrm{Mn}$, com predominância da criptomelana. Os outros constituintes minerais são a pirolusita, todorokita, gibbsita, espessartita, magnetita e nsutita. Pode-se justificar o elevado teor de Mn no minério pela predominância da criptomelana e pela presença da pirolusita. A presença da gibbsita e da espessartita justifica o expressivo teor de $\mathrm{Al}_{2} \mathrm{O}_{3}$.

Os resultados obtidos neste trabalho estão de acordo com as observações de FARIA et al. (2011) [6], que apontam a criptomelana e a todorokita como fases minerais majoritárias para o minério do Azul. Entretanto, SONRENSEN et al. (2010) encontraram a nsutita como mineral majoritário, seguido da todorokita. Uma possível explicação para tal contradição seria o fato de as amostras terem sido coletadas em períodos diferentes e, possivelmente, em diferentes frentes de lavra, uma vez que há uma diferença significativa entre as análises químicas e os difratogramas de raios-x apresentadas pelos autores.

Tabela 2: Resumo dos minerais identificados no produto Granulado de manganês proveniente da mina do Azul.

\begin{tabular}{|c|c|c|c|c|}
\hline \multirow{2}{*}{ Amostra } & \multicolumn{4}{|c|}{ Mineral Identificado } \\
\hline & $\begin{array}{l}\text { Predominante } \\
\quad(>\mathbf{4 0 \%})\end{array}$ & $\begin{array}{l}\text { Maior } \\
(<20 \%)\end{array}$ & $\begin{array}{l}\text { Menor } \\
(<10 \%)\end{array}$ & $\begin{array}{l}\text { Minoritário } \\
(<3 \%)\end{array}$ \\
\hline $\begin{array}{c}\text { Produto Granulado do } \\
\text { Azul }\end{array}$ & $\begin{array}{c}\text { Criptomelana } \\
{\left[\mathrm{KMn}_{8} \mathrm{O}_{16}\right]}\end{array}$ & $\begin{array}{c}\text { Todorokita } \\
{\left[(\mathrm{Na}, \mathrm{Ca}, \mathrm{K})_{2} \mathrm{Mn}_{6} \mathrm{O}_{12}\right.} \\
\left.\cdot 3 \mathrm{a} 4.5\left(\mathrm{H}_{2} \mathrm{O}\right)\right] \\
\text { Pirolusita } \\
{\left[\mathrm{MnO}_{2}\right]}\end{array}$ & $\begin{array}{c}\text { Gibbsita } \\
{\left[\mathrm{Al}(\mathrm{OH})_{3}\right]}\end{array}$ & $\begin{array}{c}\text { Espessartita } \\
{\left[\mathrm{Mn}_{3} \mathrm{Al}_{2}\left(\mathrm{SiO}_{4}\right)_{3}\right]} \\
\text { Magnetita } \\
{\left[\mathrm{Fe}_{3} \mathrm{O}_{4}\right]} \\
\text { N-sutita } \\
{\left[\mathrm{Mn}(\mathrm{O}, \mathrm{OH})_{2}\right]}\end{array}$ \\
\hline
\end{tabular}

A Figura 2 é uma fotomicrografia do produto Granulado do Azul, obtida com um microscópio de luz refletida, onde se observa um único grão com elevada porosidade (nódulos pretos) e numerosas trincas nucleadas a partir dos poros. O grão é constituído majoritariamente por criptomelana (massa cinzenta) sobre a qual existem cristais muito pequenos de coloração branca (elevado poder refletor) de todorokita. A Figura 3 é uma imagem de elétrons retroespalhados da mesma porção abordada pela Figura 2. Nesta Figura é possível observar a partícula com sua porosidade e trincas, entretanto não é observado nenhum contraste que possibilite diferenciar as fases presentes. 


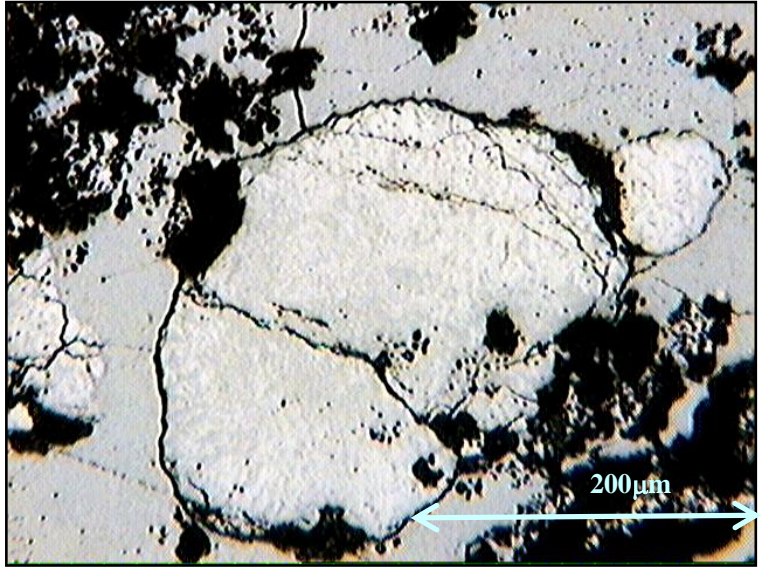

Figura 2: Fotomicrografia de luz refletida da amostra MG60 ilustrando um grão de criptomelana.

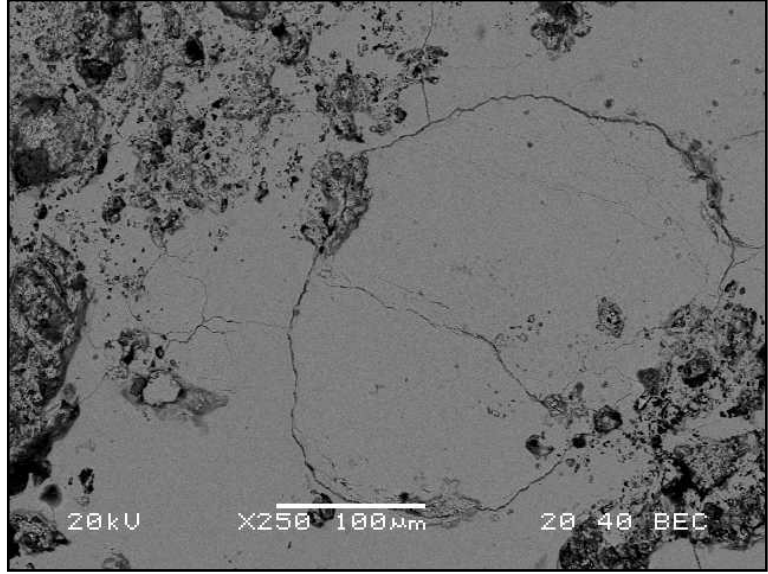

Figura 3: Imagem de elétrons retroespalhados da amostra MG60 ilustrando um grão de criptomelana.

A Tabela 3 traz os valores da porosidade e das densidades aparentes medidas por meio do picnômetro a álcool e do micropicnômetro a hélio. O minério apresenta elevada densidade aparente em função da predominância da criptomelana, um óxido de elevada densidade $\left(4,35 \mathrm{~g} / \mathrm{cm}^{3}\right)$. A diferença entre as porosidades aparentes medidas com álcool e com hélio pode ser atribuída à elevada microporosidade do minério, que apesar de interconectada, permite que o gás He penetre mais do que o álcool.

Tabela 3: Porosidade total, densidades aparentes medidas com picnômetro a álcool e micropicnômetro a hélio do produto Granulado.

\begin{tabular}{c|c|c|c}
\hline Produto Granulado do Azul & Álcool & Hélio & Porosidade \\
\hline Densidade $\left(\mathbf{g} / \mathbf{c m}^{\mathbf{3}}\right)$ & 3,55 & 3,98 & $10,9 \%$ \\
\hline
\end{tabular}

A Tabela 4 apresenta os principais resultados relacionados à área superficial e distribuição de tamanho de poros (poros com diâmetros médios entre $0,3 \mathrm{~nm}$ e $300 \mathrm{~nm}$ ), obtidos pela técnica de adsorção de nitrogênio, para o Produto Granulado. Os resultados confirmam o pequeno tamanho médio dos poros $(10,4 \mathrm{~nm})$. Esta distribuição de poros e a elevada superfície específica podem ser bons indicadores no que diz respeito à redutibilidade do Produto Granulado do Azul. Espera-se que quanto maior a porosidade, vinculada à maior superfície específica, melhor será o desempenho de redução do minério. Os valores encontrados estão em acordo com os encontrados por FARIA et al. (2012), e segundo os autores, a elevada porosidade seria um dos fatores que aliviaria a intensidade do fenômeno de crepitação dos minérios provenientes da mina do Azul em relação a outros minérios oxidados e menos porosos.

Tabela 4: Principais parâmetros definidos pela técnica BET para o produto Granulado de manganês proveniente da mina do Azul.

\begin{tabular}{c|c|c|c|c|c|c}
\hline $\begin{array}{c}\text { Amostra } \\
\text { Produto Gra- } \\
\text { nulado }\end{array}$ & $\begin{array}{c}\text { Superfície } \\
\text { Específica } \\
\left(\mathbf{m}^{\mathbf{2}} / \mathbf{g}\right)\end{array}$ & $\begin{array}{c}\text { Volume total } \\
\mathbf{d o s} \text { poros } \\
\left(\mathbf{c m}^{\mathbf{3}} / \mathbf{g}\right) \\
(\mathbf{0 , 3 - 3 0 0 n m )}\end{array}$ & $\begin{array}{c}\text { Tamanho } \\
\text { Máximo dos } \\
\text { Poros }(\mathbf{\AA})\end{array}$ & $\begin{array}{c}\text { Diâmetro } \\
\text { Médio de } \\
\text { Poros }(\mathbf{\AA})\end{array}$ & $\begin{array}{c}\text { Volume dos } \\
\text { microporos } \\
\left(\mathbf{c m}^{\mathbf{3}} \mathbf{/ g}\right) \\
(\mathbf{0 , 3 - 2 n m})\end{array}$ & $\begin{array}{c}\text { Área dos } \\
\text { Microporos } \\
\left(\mathbf{m}^{\mathbf{2}} / \mathbf{g}\right)\end{array}$ \\
\hline Azul & 11,26 & 29,40 & 1307,0 & 104,4 & 4,998 & 14,15 \\
\hline
\end{tabular}

Tendo em vista a grande importância dos fenômenos relacionados à decomposição térmica das fases minerais, a Figura 4 traz a curva de perda de massa em função da temperatura para o Produto Granulado do Azul. As linhas divisórias, destacadas em vermelho, indicam o início de algumas transformações na amostra estudada.

A primeira perda de massa acentuada, que se inicia nas proximidades de $300{ }^{\circ} \mathrm{C}$, está associada ao início da decomposição térmica das fases minerais hidratadas, neste caso, majoritariamente, da todorokita e da nsutita (A), o que está em acordo com estudos desenvolvidos por FARIA et al. 2011 e SORENSEN et al. 2010. Nas proximidades de $600{ }^{\circ} \mathrm{C}$ inicia-se a decomposição de alguns óxidos, especificamente a transforma- 
ção de $\mathrm{MnO}_{2}$ em $\mathrm{Mn}_{2} \mathrm{O}_{3}$ (B). As fases minerais criptomelana e pirolusita iniciam sua decomposição, sendo completamente consumidas até temperaturas próximas de $850{ }^{\circ} \mathrm{C}$. Nesta faixa de temperatura observa-se a maior perda de massa, o que confirma a criptomelana como fase mineral majoritária.

A variação de massa observada nas proximidades de $900{ }^{\circ} \mathrm{C}$ está associada à transformação de $\mathrm{Mn}_{2} \mathrm{O}_{3}$ em $\mathrm{Mn}_{3} \mathrm{O}_{4}$. Provavelmente a criptomelana e a pirolusita na faixa de 700 a $900{ }^{\circ} \mathrm{C}$ se transformam completamente em $\mathrm{Mn}_{2} \mathrm{O}_{3}$, que a $980^{\circ} \mathrm{C}$ inicia sua decomposição, se transformando em $\mathrm{Mn}_{3} \mathrm{O}_{4}(\mathrm{C})$. A Tabela 5 apresenta a perda de massa verificada no produto Granulado do Azul, assim como a Figura 5 apresenta um comparativo entre os difratogramas de raios-x obtidos para a amostra natural e para a amostra termicamente decomposta. Observa-se que a amostra natural apresenta seus picos de maior intensidade correspondentes à criptomelana e à todorokita, entretanto, a amostra termicamente decomposta parece ser constituída majoritariamente por $\mathrm{Mn}_{3} \mathrm{O}_{4}$ e $\mathrm{Mn}_{2} \mathrm{O}_{3}$, como também observaram FARIA et al (2012) e SORENSEN et al (2010).

Pode-se afirmar que a técnica de difratometria de raios-x se mostra insuficiente para a completa caracterização mineralógica do minério estudado, uma vez que picos de reflexão da pirolusita, todoroquita e nsutita são coincidentes com as reflexões da criptomelana. Assim sendo a presença da pirolusita, da todorokita e nsutita podem ser confirmadas por meio de procedimentos mais elaborados de microscopia óptica (minerais opacos e transparentes) e de observações das variações de massa das amostras quando submetidas a análises termogravimétricas (principalmente minerais hidratados e carbonatados).

Tabela 5: Perdas de Massa do Produto Granulado de manganês proveniente da mina do Azul.

\begin{tabular}{c|c|c|c|c|c|c}
\hline Amostra & $\mathbf{2 0 0}^{\mathbf{}} \mathbf{C}$ & $\mathbf{3 0 0}^{\mathbf{}} \mathbf{C}$ & $\mathbf{5 0 0}^{\mathbf{}} \mathbf{C}$ & $\mathbf{7 0 0}^{\mathbf{C}} \mathbf{C}$ & $\mathbf{9 0 0}^{\mathbf{C}} \mathbf{C}$ & $\mathbf{1 1 0 0}^{\mathbf{C}} \mathbf{C}$ \\
\hline Azul & $2,7 \%$ & $4,2 \%$ & $6,5 \%$ & $11 \%$ & $12,7 \%$ & $13,8 \%$ \\
\hline
\end{tabular}

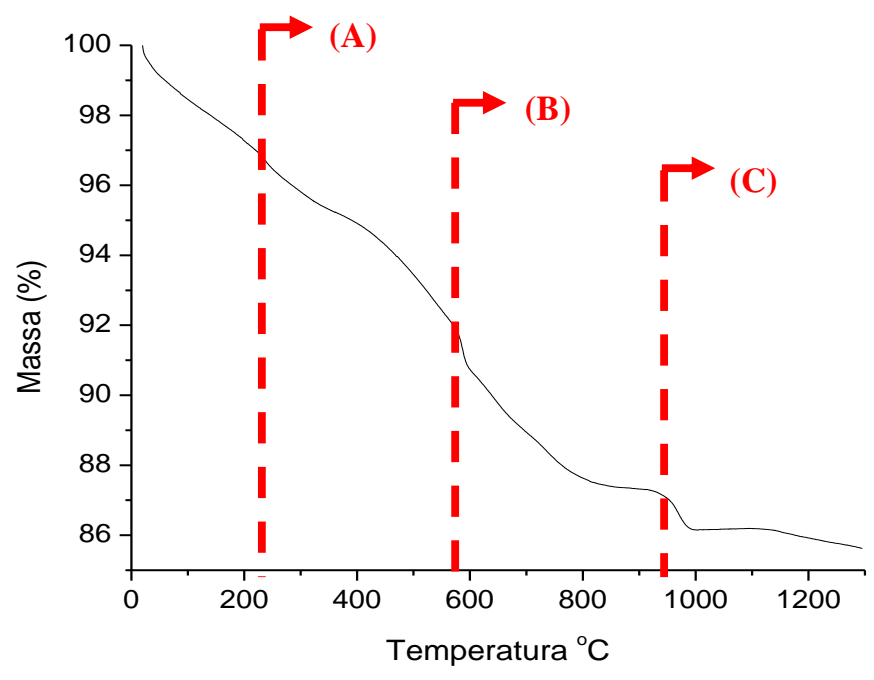

Figura 4: Perfil da perda de massa fornecido pelo ensaio de termogravimetria do Produto Granulado de Manganês proveniente da Mina do Azul. 


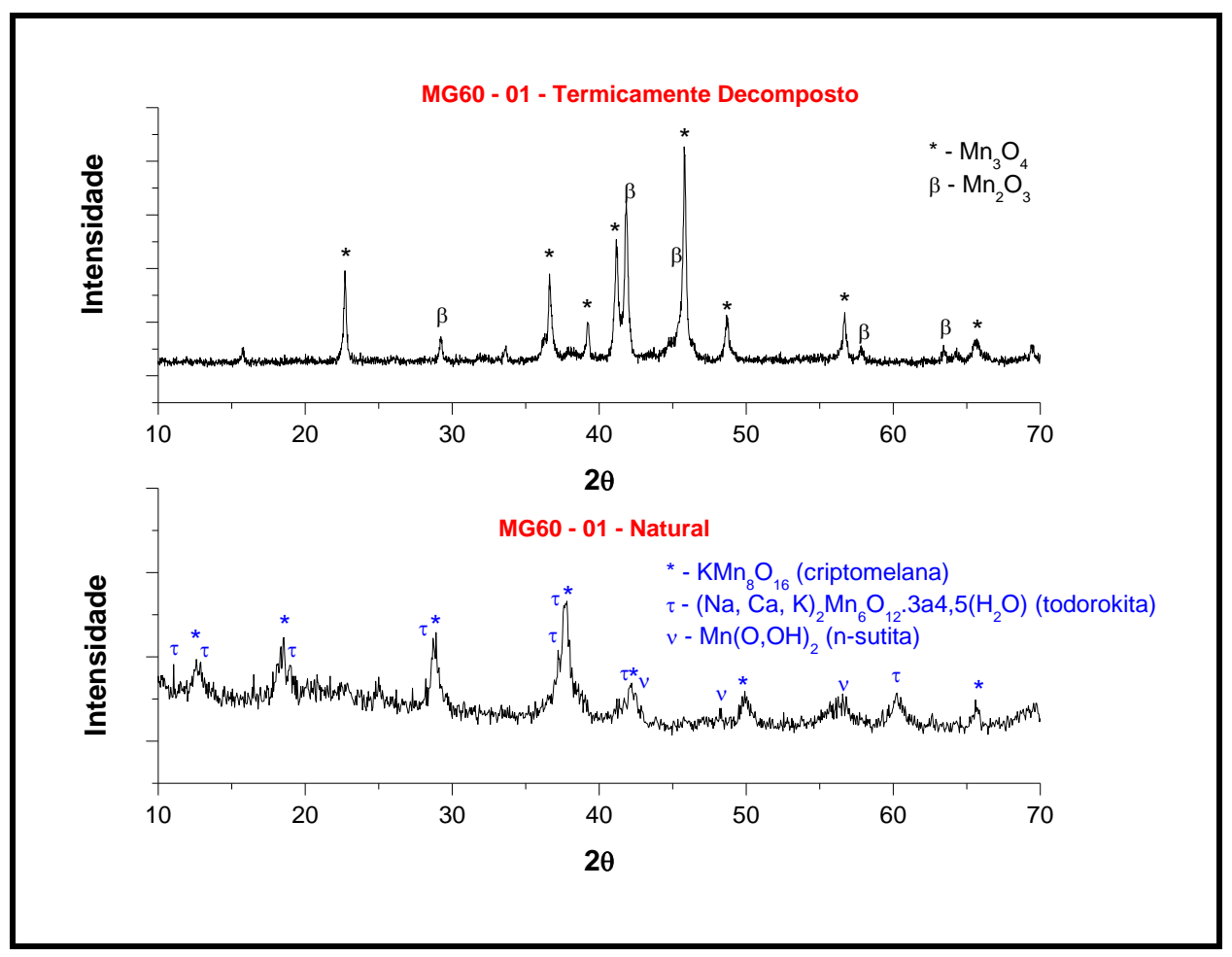

Figura 5: Comparativo entre os difratogramas de raios- $x$ do Produto Granulado do Azul antes e após a sua submissão ao ciclo térmico.

\section{CONCLUSÕES}

A distribuição granulométrica mostrou que $50 \%$ das partículas que compõem o produto Granulado do Azul se encontram abaixo de $12,5 \mathrm{~mm}$.

Em função de sua composição mineral e com base nos ensaios termogravimétricos a amostra do Granulado do Azul pode ser classificada como um minério do tipo oxidado hidratado. O Granulado do Azul tem como principal constituinte mineral a criptomelana $\left[\mathrm{KMn}_{8} \mathrm{O}_{16}\right]$, e entre outros importantes a pirolusita $\left[\mathrm{MnO}_{2}\right]$ e a todorokita $\left[(\mathrm{Na}, \mathrm{Ca}, \mathrm{K})_{2} \mathrm{Mn}_{6} \mathrm{O}_{12} \cdot 3-4.5\left(\mathrm{H}_{2} \mathrm{O}\right)\right]$.

O produto Granulado estudado pode ser considerado como de elevado teor de manganês por apresentar teor médio de $47,68 \%$, portanto bom para utilização em fornos elétricos de redução na produção de FeMnAC.

Durante o aquecimento ao ar do minério Granulado do Azul, nas proximidades de $600{ }^{\circ} \mathrm{C}$, inicia-se a decomposição térmica dos óxidos criptomelana $\left[\mathrm{KMn}_{8} \mathrm{O}_{16}\right]$ e pirolusita $\left[\mathrm{MnO}_{2}\right]$, transformando-se em $\mathrm{Mn}_{2} \mathrm{O}_{3}$. Nas proximidades de $980{ }^{\circ} \mathrm{C}$ tem início a transformação de $\mathrm{Mn}_{2} \mathrm{O}_{3}$ em $\mathrm{Mn}_{3} \mathrm{O}_{4}$. As perdas de massa deste Granulado, quando aquecido a $700{ }^{\circ} \mathrm{C}$ e a $1100^{\circ} \mathrm{C}$, são $11 \%$ e $13,8 \%$, respectivamente.

A área superficial elevada permite projetar elevada reatividade em forno de redução. $\mathrm{O}$ tamanho diminuto dos poros (médio de $10 \mathrm{~nm}$ ) pode ser um obstáculo para a permeação de gases de redução. Os dados de micropicnometria com hélio indicam que os poros são interconectados, portanto a redução com gases de molécula pequena, como hidrogênio, deve ser muito eficiente. Moléculas maiores, como CO, no entanto, podem não atingir o interior do granulado adequadamente.

\section{AGRADECIMENTOS}

Os autores agradecem a Vale, por ceder gentilmente as amostras, a redemat/UFOP e a agência CAPES.

\section{BIBLIOGRAFIA}

[1] OLSEN, S.E, TANGSTAD, M, LINDSTAD, T., "Production of ferromanganese alloys in the submerged arc furnace”, TRONDHEIM, NORWAY, pp., 247, 2007. 
[2] CHIAVERINI, V. “Aços e ferros fundidos”, São Paulo: ABM, 6ª Edição, 1990.

[3] CHAUDHARY, P.N., GOEL, R.P., ROY, G.G., "Dephosphorization of high carbon ferromanganese using $\mathrm{BaCO}_{3}$ based fluxes", Ironmaking and Steelmaking, v. 28, n. 5, pp. 396-403, 2001.

[4] FARIA, G.L., Estudo da intensidade de crepitação de minérios granulados de manganês do Brasil, dissertação de M.Sc., UFOP/REDEMAT, Ouro Preto, MG, Brasil, 2008

[5] REIS, É.L., FARIA, G.L., ARAÚJO, F.G.D.S., et al, "Characterization of a Brazilian manganese ore typology", Revista Escola de Minas, v. 63 n. 3, pp. 517-521, julho-setembro 2010

[6] SORENSEN, B., GAAL, S., RINGDALEN, E., et al., "Phase compositions of manganese ores and their change in the process of calcination", International Journal of Mineral Processing v. 94, n. 3-4, pp. 101-110, April 2010.

[7] FARIA, G.L, JANNOTTI, J.N., ARAÚJO, F.G.S, "Decrepitation behavior of manganese lump ores", International Journal of Mineral Processing, v. 102-103, pp. 150-155, January 2012.

[8] AMEC, “CVRD reserve audit report”, Appendix E, pp. 100, 2006. 